PEREIRA JUNIOR, G., SOUZA, F.S. e BARBOSA, P.S. Perfil mercadológico do segmento de produtos veterinários para cães e gatos na Cidade de São João da Barra - RJ. PUBVET, Londrina, V. 8, N. 3, Ed. 252, Art. 1669, Fevereiro, 2014.

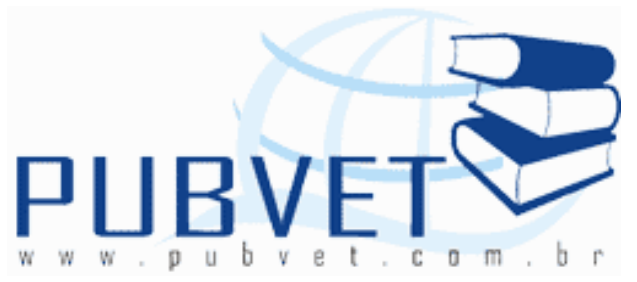

PUBVET, Publicações em Medicina Veterinária e Zootecnia.

\title{
Perfil mercadológico do segmento de produtos veterinários para cães e gatos na Cidade de São João da Barra - RJ
}

\author{
Geraldo Pereira Junior ${ }^{1}$, Fábio Silva de Souza ${ }^{2}$ e Paula de Sousa Barbosa ${ }^{3}$
}

${ }^{1}$ Professor do Instituto Federal Fluminense de Ciência e Tecnologia - IFF.

E-mail: geraldoinpa@hotmail.com

${ }^{2}$ Prof. do curso de medicina veterinária da Escola Superior Batista do Amazonas. E-mail: souzamedvet@yahoo.com.br

${ }^{3}$ Aluna de doutorado do Instituto nacional de Pesquisas da Amazônia - INPA. E-mail: manatee_psbd@hotmail.com.

\section{Resumo}

A verticalização das cidades e a vida mais solitária têm contribuído para movimentar o mercado de pequenos animais domésticos. $O$ crescimento médio neste setor está em torno de vinte por cento ao ano e a tendência é de crescimento ainda maior a curto e médio prazo. Para acompanhar esta evolução, é necessário que os serviços prestados pelos empresários deste setor apresentem qualidade e competitividade. Mas para que os serviços prestados apresentem qualidade é necessário o conhecimento do perfil dos clientes, sendo identificadas suas reais necessidades. $O$ objetivo desse estudo foi conhecer o perfil mercadológico do segmento de pet shop na cidade de São João da Barra, Estado do Rio de Janeiro. A metodologia empregada foi qualitativa, sendo aplicados cinquenta questionários aos consumidores e doze 
PEREIRA JUNIOR, G., SOUZA, F.S. e BARBOSA, P.S. Perfil mercadológico do segmento de produtos veterinários para cães e gatos na Cidade de São João da Barra - RJ. PUBVET, Londrina, V. 8, N. 3, Ed. 252, Art. 1669, Fevereiro, 2014.

questionários aos comerciantes. A coleta de dados seguiu roteiros de entrevistas semi-estruturadas e observações diretas. Esse estudo trouxe considerações relevantes tanto para a academia como para a comunidade empresarial. Primeiro, por mostrar a aplicação da teoria de Marketing em um contexto particular, em segundo, por ressaltar a necessidade de uma maior profissionalização do setor no mercado de pequenos animais. Conclui-se com este estudo que existe um despreparo dos comerciantes em aplicar conceitos básicos de marketing e estratégia comercial, não atendendo a demanda dos consumidores por produtos e serviços especializados em pequenos animais.

Palavras-chave: Estudo de Marketing, mercado pet shop, orientação estratégica.

\section{Profile market segment of veterinary products for dogs and cats in the city of São João da Barra - RJ}

\section{Abstract}

The vertical integration of cities and more solitary life have helped to move the market for small domestic animals. The average growth in this sector is around twenty percent per year and the trend is even greater growth in the short and medium term. To support this change, it is necessary that the services provided by entrepreneurs in this sector show quality and competitiveness. But for the present quality services is necessary to know the profile of the customers, identifying their real needs. The aim of this study was to know the market profile of the segment pet shop in São João da Barra, State of Rio de Janeiro. The methodology was qualitative and sixty questionnaires applied to consumers and twelve questionnaires to traders. Data collection followed roadmaps semi-structured interviews and direct observations. This study brought considerations relevant for both academia and the business community. First, to show the application of the theory of Marketing in a particular context, second, by emphasizing the need for greater professionalism in the market sector of small animals. It is concluded from this 
PEREIRA JUNIOR, G., SOUZA, F.S. e BARBOSA, P.S. Perfil mercadológico do segmento de produtos veterinários para cães e gatos na Cidade de São João da Barra - RJ. PUBVET, Londrina, V. 8, N. 3, Ed. 252, Art. 1669, Fevereiro, 2014.

study that there is a lack of preparation traders to apply basic concepts of marketing and commercial strategy, not meeting the demand of consumers for products and services specialized in small animals.

Keywords: Marketing Study, pet shop market, strategic orientation.

\section{INTRODUÇÃO}

A verticalização das cidades e a vida mais solitária têm contribuído para movimentar o mercado de pequenos animais. O segmento de pets cresce cerca de $20 \%$ ao ano - segundo profissionais do setor - e isso ocorre, em parte, em decorrência da mudança do perfil das pessoas (ZOONEWS, 2005).

O mercado de produtos veterinários e afins no Brasil, apesar de relativamente recente, dá sinais de que, dentro em breve, estará próximo de alcançar o sucesso obtido em outros países, onde esta atividade é mais desenvolvida. Isso é devido ao enorme potencial de consumo da população e a maior consciência dos cuidados com os animais de estimação, principalmente pela população de maior poder aquisitivo e maior grau de instrução (ANTUNES, 1998).

Evidente que, diante dessa realidade, quem mais ganha com a soma desses fatores são os chamados "pet shops" - lojas especializadas em oferecer produtos e serviços para animais domésticos de pequeno e médio porte. Para se ter uma idéia da relevância que esse setor vem ganhando nos últimos tempos na economia do País, basta verificar que, desde 1995, o mercado cresce a uma média anual de $17 \%$, faturando cerca de US $\$ 1,5$ bilhão ao na o(TRAVAGIN; GIACOMINI-FILHO, 2011). O que, a princípio, pode parecer um número surpreendente ganha fundamento quando se analisa que tal segmento atende a uma "população" de cerca de 25 milhões de cães, 11 milhões de gatos, 4 milhões de pássaros e, ainda, 500 mil aquários espalhados por todo o Brasil - segundo dados da Associação de Produtos e Prestadores de Serviços ao Animal (ASSOFAUNA, 2006). 
PEREIRA JUNIOR, G., SOUZA, F.S. e BARBOSA, P.S. Perfil mercadológico do segmento de produtos veterinários para cães e gatos na Cidade de São João da Barra - RJ. PUBVET, Londrina, V. 8, N. 3, Ed. 252, Art. 1669, Fevereiro, 2014.

Diante da expansão do mercado de pet shop no Brasil existe a necessidade de especialização na área de marketing veterinário. Esta área do conhecimento está voltada para os conceitos de gerenciamento de estabelecimentos veterinários, marketing pessoal, custos de operação, concorrência de mercados, dentro dos diferentes ramos da profissão. Trata-se de uma abertura para os caminhos e as possibilidades no mercado de trabalho, sendo uma atividade que visa satisfazer as necessidades e desejos pessoais, por meio de processos de troca dos consumidores e dos serviços prestados (AAKER et al., 2001).

O marketing é indispensável para o crescimento de qualquer empresa cujo objetivo principal é prestar serviços de qualidade, ampliando e diversificando o mercado de atuação (KARSAKLIAN, 2004). Esta diversificação está relacionada com a ampliação no escopo do negócio ao promover a atuação em campos inteiramente novos sob o ponto de vista mercadológico.

Existe a necessidade de se elaborar um plano estratégico antes de abrir um negócio autônomo. Este plano estratégico tem como objetivo principal avaliar a estrutura dos mercados e traçar um caminho a ser percorrido para que os objetivos empresariais sejam alcançados (KOTLER, 2000). Para isso, é imprescindível o conhecimento do público alvo a ser atendido, identificando suas reais necessidades e seus anseios. Este conhecimento pode fazer toda diferença diante da competitividade comercial. Isso se deve ao fato de se atender especificamente aquilo que os clientes procuram ao buscarem serviços específicos.

Uma região brasileira que tem apresentado grande potencial de crescimento nos últimos anos é o Norte Fluminense, principalmente a cidade de São João da Barra. Isso está relacionado com a implantação de um porto nesta cidade. Este empreendimento aquecerá a economia da região através da geração de renda e emprego. Desta forma, o comércio local deverá sofrer mudanças positivas em termos de relação compra e venda.

Um dos grandes potenciais de comércio que se observa na cidade de São João da Barra é o setor de pequenos animais, principalmente cães e gatos. 
PEREIRA JUNIOR, G., SOUZA, F.S. e BARBOSA, P.S. Perfil mercadológico do segmento de produtos veterinários para cães e gatos na Cidade de São João da Barra - RJ. PUBVET, Londrina, V. 8, N. 3, Ed. 252, Art. 1669, Fevereiro, 2014.

Fica evidente a grande oportunidade para implantação de um negócio na área de pet shop. Contudo para que este negócio obtenha eficácia empresarial é indispensável a caracterização do mercado de pet shop nesta cidade (KOTLER; GARY, 1998). Somente assim, será possível oferecer o melhor serviço ao consumidor, engrandecendo tanto o mercado local, por oferecer um serviço de qualidade, quanto ao próprio comerciante que terá um cliente satisfeito e fiel.

O objetivo deste estudo foi identificar e caracterizar o perfil geral do consumidor local, em termos de consumo mensal com animais de estimação e principais serviços requeridos na cidade de São João da Barra, RJ.

\section{METODOLOGIA}

\subsection{Caracterização do Local de Estudo e Público Alvo}

A pesquisa foi conduzida na Cidade turística de São João da Barra, município brasileiro do estado do Rio de Janeiro. Localiza-se no norte fluminense e de acordo com o censo do IBGE (2010) possui cerca de 130.000 habitantes.

O estudo foi realizado com proprietários de pet shop (que atuam fornecendo serviços ou produtos veterinários) e moradores locais (residentes do município de São João da Barra).

\subsection{Metodologia}

A coleta de dados foi baseada no modelo de entrevistas semiestruturada. Este tipo de entrevista tem como referência uma lista de questões que devem ser respondidas preferencialmente numa ordem particular, mas com flexibilidade (ALEXIADES, 1996). Este procedimento é útil quando nem todas as respostas precisam ser quantificadas, dando a chance para o entrevistado incluir mais detalhes ou fazer associações com outras respostas (HUNTINGTON, 2000). 
PEREIRA JUNIOR, G., SOUZA, F.S. e BARBOSA, P.S. Perfil mercadológico do segmento de produtos veterinários para cães e gatos na Cidade de São João da Barra - RJ. PUBVET, Londrina, V. 8, N. 3, Ed. 252, Art. 1669, Fevereiro, 2014.

Foi aplicado um questionário (Questionário A) com 15 questões a doze comerciantes de produtos e serviços veterinários, correspondendo a $100 \%$ dos comerciantes de pet shop na cidade de São João da Barra. A aplicação do questionário foi realizada por meio de visitas nos pontos comerciais da cidade, onde foi exposto o objetivo da pesquisa e feito o convite para a participação. Após os comerciantes concordarem em participar do estudo, foi aplicado o questionário de acordo com a disponibilidade de tempo do entrevistado.

Aplicação de um questionário com 11 questões (Questionário B) a 50 moradores da cidade de São João da Barra, sendo eles aplicados quando os consumidores estavam saindo das lojas pet shop. Ao abordar o consumidor, foi estabelecido contato direto para exposição do objetivo do estudo. Então era feito o convite para a participação do estudo. Quando o entrevistado concordava em participar e havia disponibilidade momentânea, foi aplicado o questionário no mesmo instante. Quando não havia disponibilidade do participante naquele momento, foi feito o convite para participação em outra ocasião, sendo marcados dia e local de acordo com a disponibilidade do entrevistado.

Todos os entrevistados preencheram e assinaram um termo de autorização para realização das perguntas.

\subsubsection{Questionários}

Questionário A - Aplicado a comerciantes.

1) Qual a linha de produto que tem maior saída?

2) Qual época do ano os produtos possuem maior saída?

3) Quais os tipos de serviços oferecido aos seus clientes?

4) Qual o produto / serviço com maior margem de lucro?

5) Quais são as formas de pagamento dos produtos e serviços?

6) Qual é o seu público alvo?

7) Você possui serviço de "disk ração"? 
PEREIRA JUNIOR, G., SOUZA, F.S. e BARBOSA, P.S. Perfil mercadológico do segmento de produtos veterinários para cães e gatos na Cidade de São João da Barra - RJ. PUBVET, Londrina, V. 8, N. 3, Ed. 252, Art. 1669, Fevereiro, 2014.

8) Quais as dificuldades encontradas no negócio?

9) Quais as facilidades encontradas no negócio?

10) Qual o meio de divulgação da loja? Por quê?

11) São feitas promoções na loja?

12) Qual é o diferencial da sua loja e como foi implantado?

13) Conhece o comportamento de mercado da concorrência?

14) Como os clientes avaliam seu atendimento?

15) Você classifica os tipos de clientes de acordo com consumo?

Questionário B - Aplicado a consumidores.

1) Idade

2) Sexo

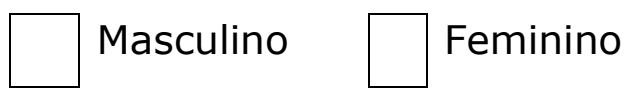

3) Média de pessoas por família?

4) Você tem animal de estimação?

\section{Sim ( ) Não ( )}

Qual?

Quantos? /raça?

Idade? / Sexo?

5) Qual o gasto total médio com animais/mês?

6) Recebem serviço veterinário em domicílio

7) Qual fator seria mais relevante para você não utilizar os serviços veterinários?

( ) Localização ( ) estrutura ( ) preço alto ( ) confiança ( ) outros/ Quais? 
PEREIRA JUNIOR, G., SOUZA, F.S. e BARBOSA, P.S. Perfil mercadológico do segmento de produtos veterinários para cães e gatos na Cidade de São João da Barra - RJ. PUBVET, Londrina, V. 8, N. 3, Ed. 252, Art. 1669, Fevereiro, 2014.

\section{RESULTADOS E DISCUSSÃO}

O resultado das entrevistas com os 12 comerciantes de pet shop da cidade de São João da Barra, RJ.

Os 12 comerciantes entrevistados indicaram o produto mais vendido é ração para animais domésticos. Isso sugere que existem muitos criadores de pequenos animais na cidade de São João da Barra. Este fato pode estar relacionado com o estilo de vida dos moradores, sendo na sua maioria pessoas de idade avançada que buscam qualidade de vida nas cidades tranquilas do interior, optando por possuir um animal de companhia. E também com a cultura da população de cuidar de animais de estimação, priorizando a alimentação destes basicamente com ração balanceada.

Três comerciantes informaram que a saída de seus produtos permanecia semelhante em todo o ano porém nove proprietários relataram que o verão é a época do ano que ocorre maior número de vendas. Isso já era previsto, já que São João da Barra é uma cidade litorânea e turística, servindo de atrativo para muitos turistas do estado do Rio de Janeiro e outros estados brasileiros, principalmente durante o verão. Muitos destes veranistas possuem animais de estimação e fazem questão de levá-los durante esta temporada, aquecendo as vendas do comércio local. Vale a pena ressaltar ainda que no final do ano os trabalhadores recebem décimo terceiro salário e férias remuneradas, possuindo maior poder de compra. Isso também pode contribuir para o aumento das vendas no comércio de pequenos animais durante o verão.

Os serviços oferecidos pelos comerciantes de pequenos animais na cidade de São João da Barra são básicos sendo limitados a venda de medicamentos e ração em todos as lojas e ao banho e tosa sendo oferecido em nove lojas e esta atividade proporcionando uma maior margem de lucro para apenas $25 \%$ dos comerciantes que a oferecem enquanto que a venda de medicamentos e de ração a margem de lucro é maior para $50 \%$ dos empresários. Segundo os comerciantes, existe uma procura muito intensa dos criadores dos animais por atendimento veterinário especializado. Contudo há 
PEREIRA JUNIOR, G., SOUZA, F.S. e BARBOSA, P.S. Perfil mercadológico do segmento de produtos veterinários para cães e gatos na Cidade de São João da Barra - RJ. PUBVET, Londrina, V. 8, N. 3, Ed. 252, Art. 1669, Fevereiro, 2014.

um déficit no atendimento veterinário na cidade devido a baixa oferta de profissionais médicos veterinários, sendo que apenas um profissional que presta serviços veterinários é especialista em caninos e felinos, o que força os proprietários em casos de emergência procurar profissionais em outras cidades com uma oferta maior de profissionais, não permitindo então que o capital circule na cidade de São João da Barra.

Outro fator identificado neste estudo foi a ausência de um atendimento voltado para um público alvo por parte de nove comerciantes entrevistados e o desconhecimento de todos os entrevistados quanto ao comportamento de mercado envolvendo a concorrência. Porém os 12 proprietários afirmaram não classificar seus clientes quanto ao que consumiam e como estes avaliavam seu atendimento. Segundo relatos dos entrevistados: "cliente é tudo igual", independente do que consome e/ou quanto consome. Este comentário evidenciou uma falta de preparo dos comerciantes para este novo segmento de mercado. Isso faz com que diferentes tipos de clientes sejam tratados da mesma maneira, evidenciando falta de estratégia de mercado e de empreendedorismo, sendo indicado por três empresários que o seu público alvo teria um baixo poder aquisitivo.

Embora, três comerciantes apontarem que um diferencial para seu negócio fossem a qualidade enquanto outros três aparência que pudessem ajudar na atração de clientes e nove entrevistados realizavam promoções em suas lojas. As promoções eram utilizadas para manter a fidelidade e satisfação dos clientes. Uma estratégia muito comentada diz respeito ao serviço de banho e tosa, onde o proprietário ganhava um banho para o animal a partir de determinado número solicitações deste mesmo serviço. Alguns relataram não se importar caso o cliente não tenha ficado satisfeito com o atendimento ou serviço prestado. Outros afirmaram ainda, que existia uma clientela antiga e por este motivo, deve estar satisfeita.

Estes resultados refletem nas formas de cobrança pelos serviços prestados como foi observado para as opções de pagamento dadas aos clientes oferecidas por $100 \%$ dos comerciantes era em dinheiro e três comerciantes 
PEREIRA JUNIOR, G., SOUZA, F.S. e BARBOSA, P.S. Perfil mercadológico do segmento de produtos veterinários para cães e gatos na Cidade de São João da Barra - RJ. PUBVET, Londrina, V. 8, N. 3, Ed. 252, Art. 1669, Fevereiro, 2014.

também ofereciam a opção de débito em cartões. Logo as dificuldades mais apontadas por $50 \%$ dos comerciantes entrevistados foi relacionada ao pedido de venda no fiado. Este problema está ligado com a inadimplência do consumidor. Por se tratar de uma cidade pequena e interiorana, onde as pessoas se conhecem, é comum o pedido de venda no fiado com a intenção de pagar no final do mês. Segundo os entrevistados, muitos destes pedidos não são honrados e, além de perder a mercadoria, os comerciantes acabam perdendo o cliente que deixam de frequentar a loja. Três entrevistados também colocaram fornecedores e outros três o capital como dificuldades para os negócios.

Como forma de divulgação dos estabelecimentos a propaganda por meio do rádio era o meio escolhido por $50 \%$ dos entrevistados. Segundo eles, é o veículo de comunicação que tem demonstrado melhores resultados, além de possuir investimento relativamente baixo. Este fato se dá ao hábito da população em escutar rádio, sendo este um importante instrumento de divulgação e serviços. Outro método de divulgação relatado foi a panfletagem utilizado por quatro comerciantes e tem sido utilizado devido o baixo valor de utilização e de ampla abrangência sendo facilmente aplicável, pela baixa densidade demográfica da cidade. Dois comerciantes não utilizavam nenhuma forma de divulgação de seus estabelecimentos.

Os resultados encontrados na entrevista demonstram que os comerciantes não aplicam conhecimentos de marketing voltados para estratégia comercial. Falta informação e/ou aplicação destes conceitos. Isso demonstra que o mercado apresenta oportunidade de trabalho para empreendedores que pretendam aplicar conhecimentos de marketing como estratégia de comercialização de produtos veterinários. Isso está de acordo com o trabalho de Engel et al. (2000) ao informar que estudos de marketing são usados para identificar e definir oportunidades e problemas de mercado e melhorar a compreensão do marketing como processo. Concorda ainda com Churchill e Peter (2003) que entende a pesquisa de mercado como prática indispensável para especificar, coletar, analisar e interpretar as informações 
PEREIRA JUNIOR, G., SOUZA, F.S. e BARBOSA, P.S. Perfil mercadológico do segmento de produtos veterinários para cães e gatos na Cidade de São João da Barra - RJ. PUBVET, Londrina, V. 8, N. 3, Ed. 252, Art. 1669, Fevereiro, 2014.

para auxiliar a administração no entendimento de determinado ambiente de mercado, na identificação de seus problemas e oportunidades.

Em relação ao resultado das entrevistas realizadas com os moradores do local, consumidores usuários de serviços e produtos de pet shop da cidade de São João da Barra, RJ, foi verificado que a faixa etária está entre 30 a 40 anos, sendo que $70 \%$ dos entrevistados foi do sexo feminino.

Isso demonstra que existe uma tendência das mulheres possuírem animais de estimação. Esta tendência aponta para uma segmentação do mercado pet com forte potencial. Isso porque as mulheres por terem um instinto maternal cuidam de seus animais de estimação como um filho, sendo mais criteriosas ao escolher os produtos e serviços oferecidos.

A entrevista demonstrou que a média é de três pessoas por família, havendo uma preferência por cães por $75 \%$ dos consumidores participantes com uma média por família de dois animais em comparação aos gatos com uma média por família de um animal. Segundo os entrevistados os cães, além de servirem de companhia, são utilizados como animal de guarda. Isso pode explicar esta preferência. Pode ser citado o fato de muitas residências possuírem pássaros de gaiola, sendo que os gatos são, muitas vezes, vistos como ameaça por causa de suas características predadoras.

Dos $75 \%$ de consumidores entrevistados que possuíam cães a preferência era por cães machos (60\%) quando comparado com fêmeas está relacionada com aspectos reprodutivos, sendo que o cio nas fêmeas foi relatado como um período problemático. Com felinos a preferência é por fêmeas $(70 \%)$, sendo que a maior parte dos entrevistados prefere gatas a gatos. Esta preferência também parece estar relacionada com características reprodutivas. Já que, segundo os entrevistados, gatos machos costumam andar bastante a noite, brigam muito e às vezes até desaparecem. Enquanto que as fêmeas seriam mais "tranquilas".

O gasto total médio com a manutenção dos animais levantado a partir dos entrevistados foi de $R \$ 150,00$ reais por mês. Segundo os entrevistados, o item de maior custo é a ração. Isso está de acordo com a informação relatada 
PEREIRA JUNIOR, G., SOUZA, F.S. e BARBOSA, P.S. Perfil mercadológico do segmento de produtos veterinários para cães e gatos na Cidade de São João da Barra - RJ. PUBVET, Londrina, V. 8, N. 3, Ed. 252, Art. 1669, Fevereiro, 2014.

pelos comerciantes ao discriminarem a ração como item de maior venda. Segundo os consumidores, o veterinário só é solicitado quando existe real necessidade, não participando efetivamente dos gastos mensais.

Apenas 95\% dos entrevistados não recebe atendimento veterinário em domicílio. Segundo estes não existe este tipo de serviço disponível adequadamente na cidade. Quando perguntados sobre o interesse neste serviço, a resposta positiva foi unânime. Isso demonstra que existe uma grande demanda por este serviço na cidade de São João da Barra que precisaria ser atingida e de forma adequada.

Dos entrevistados, $80 \%$ citaram o alto custo como principal fator para não utilizar os serviços do médico veterinário periodicamente. Esta informação é importante, pois pode se transformar em um diferencial de mercado, sendo que existe possibilidade de se trabalhar a um valor de consulta competitivo ao se conseguir diminuir os custos fixos e variáveis do empreendimento.

\section{CONCLUSÃo}

Existe um despreparo por parte dos comerciantes da cidade de São João da Barra, RJ, que desconhecem conceitos básicos de marketing e estratégia de mercado não permitindo que este potencial de mercado seja suprido de forma eficiente e satisfatória tanto para o consumidor quanto para os comerciantes.

\section{REFERÊNCIAS}

AAKER, D.; KUMAR, E.; DAY, E. Pesquisa de Marketing. São Paulo: Atlas, 2001.

ALEXIADES, M. Collecting ethnobotanical data: an introduction to basic concepts and techniques. In: Alexiades, M. N. (Ed). Selected guidelines for ethnobotanical research: a field manual. The New York Botanical Garden, New York, 1996. p. 53-94.

ANTUNES, N. Perpesctivas do setor. Grupemef. Ano 20, n.20, março/abril.1998. Disponível em: <http://www.grupemef.com.Br/revista/materia.php?id_tb_ver_revista_pk=5>. Acesso em: 8 out de 2011. 
ASSOFAUNA - Associação dos revendedores de produtos, prestadores de serviço e defesa destinados ao uso animal. 2006. Disponível em: <http://www.petbr.com.br/asso1.asp>. Acesso em: 25 ago de 2011.

CHURCHILL, G.; PETER, P. Marketing: criando valor para o cliente. São Paulo: Saraiva, 2003.

ENGEL, J.; BLACKWELL, R.; MINIARD, P. Comportamento do consumidor. 8. ed. Rio de Janeiro: LTC, 2000.

HUNTINGTON, P. H. Using traditional ecological knowledge in science: methods and applications. Ecological Applications, v. 10, n. 5, p. 1270-1274. 2000.

IBGE. INSTITUTO BRASILEIRO DE GEOGRAFIA E ESTATÍstICA. Censo populacional brasileiro 2010. Disponível em: <http://www.censo2010.ibge.gov.br/riodasostras.populacao>. Acesso em: 26 jun de 2011.

KARSAKLIAN, E. Comportamento do consumidor. São Paulo: Atlas, 2004.

KOTLER, P.; GARY, A. Princípios de Marketing. 7 ed. Rio de Janeiro: Prentice-Hall do Brasil. 1998. p. 318-322.

KOTLER, P. Administração de Marketing. 10 ed. São Paulo: Prentice-Hall, 2000.

TRAVAGINI, R. B.; GIACOMINI-FILHO, G. A comunicação de merchandising no mercado de petshop. COMUNICON. 2011. P. 1-12.

ZOONEWS. Mercado de pequenos animais cresce $\mathbf{2 0} \%$ ao ano. Folha de Londrina. Disponível em: <http://www.zoonews.com.br/noticias2/noticia.php?idnoticia=108873>.Acesso em: 10 nov de 2011. 